\title{
Usability Testing of a Customizable Library Web Portal
}

\author{
Steve Brantley, Annie Armstrong, and \\ Krystal M. Lewis
}

The popularity of customizable Web sites in libraries has increased librarians' interest in supplementing user services with portal technology. The open source-software MyLibrary gives the librarian control over the resources directed to users based on their interests. University of Illinois at Chicago librarians developed My Chicago Library as a way to streamline user access to library resources. A usability study designed around common task categories tested the participants' abilities to customize a personal library Web page, understand the resource categories as defined by librarians, and manage the discipline-specific content available in the portal.

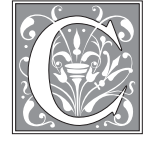

ustomizable Web pages are now the rule rather that the exception on many library Web sites. Article databases and online library catalogs retain users' searches or save lists in "book-bags." Library catalogs give users control of their patron record and circulation data. Static library Web sites are complemented by database-driven sites, or information gateways, frequently referred to as portals. Portals are Web pages that permit users to consolidate Web sites and resources pertaining to their individual needs and preferences. My Yahoo! ${ }^{\mathrm{TM}}$ is an example of a portal where users customize their page to display links and information of interest, such as business news, television listings, or gardening tips. Portals serve library patrons by highlighting highquality online information sources and streamlining access to frequently used Web sites and library resources, thereby reducing the phenomenon of information overload that can distract and confuse library patrons.

In July 2001, librarians at the University of Illinois at Chicago (UIC) received a grant funded through the State of Illinois Library Services and Technology Act to create a customizable library Web portal for use by member libraries of the Chicago Library System, a consortium of public, school, academic, and special libraries (now called Metropolitan Library System). After investigating portal products, the team chose to adapt the MyLibrary portal to meet the grant requirements.

Steve Brantley is an Assistant Reference Librarian and Assistant Professor in the Daley Library at the University of Illinois at Chicago; e-mail: jbrant1@uic.edu. Annie Armstrong is an Assistant Reference Librarian and Assistant Professor in the Daley Library at the University of Illinois at Chicago; e-mail: annie@uic.edu. Krystal M. Lewis is an Assistant Reference Librarian, Acting Assistant Special Collections Librarian, and Assistant Professor in the Daley Library at the University of Illinois at Chicago; e-mail: kmlewis1@uic.edu. 
MyLibrary was developed by a team at North Carolina State University through a grant from the National Science Foundation Digital Library Initiative. MyLibrary is an open-source project. Open-source software products are free or inexpensive programs which software developers may download to modify or enhance, providing they allow other developers access to their modifications. The MyLibrary portal organizes content according to broad functional areas. MyLibrary creates a gateway to library resources, including subscription databases, online journals, selected Internet resources, and user's bookmarks. When logged in, the user customizes the design and content of his or her page within parameters set by librarians. Librarians can design the MyLibrary portal to allow users a great deal of customization or very little. Resources and services considered essential by librarians can be included in a users' page in such a way that they cannot remove them. Moreover, librarians can choose to include or exclude any section of the portal deemed useful or beyond the scope of local collections or services.

UIC's team modified and enhanced MyLibrary, renaming it My Chicago Library. My Chicago Library contains four different versions of MyLibrary, individualized for school, special, public, and academic libraries. After developing My Chicago Library, the UIC team speculated about the effectiveness of the portal and whether it was easy to customize and to use. New questions arose:

- Are students interested in using a customizable resource portal to conduct research?

- Are the portal features intuitive and easily personalized?

- Does My Chicago Library assist in the research process?

To help answer these questions, the investigators conducted a usability study on UIC's academic version of the portal, populated with commercial resources licensed by UIC and with information tools created by UIC librarians such as subject pathfinders. The study had four goals: to determine the clarity of the customization features and ease of navigation, to gather qualitative feedback on the layout and content of the portal, to identify areas needing improvement, and to measure students' perceptions of the portal as a tool for research. This paper presents the results of that study.

\section{Review of the Literature}

At the time of writing, the body of research on measuring the effectiveness of customizable library Web portals through usability testing is limited. However, those implementing or evaluating customizable library Web portals can draw on studies pertaining to various aspects of open-source software, portals, usability testing, and the MyLibrary software. Some articles explore the usability of open-source software in general. In addition, numerous usability tests measure the efficacy of use of library Web sites by different user populations. Multiple articles evaluate nonlibrary Web portals, and several articles evaluate portals built using the MyLibrary software developed by the team at North Carolina State University (NCSU), either anecdotally or though evaluative methods other than usability testing.

In "The Usability of Open Source Software," David M. Nichols and Michael B. Twidale suggested that developers of open-source software have historically placed more emphasis on technical functionality of the software than on effective user-centered design. ${ }^{1}$ They claimed that, in general, open-source software developers create applications without focusing on usability. Thus, consecutive releases of the software contain usability problems that could have been avoided if developers had given initial attention to user-centered design. Nichols and Twidale offered several approaches to improving the usability of open-source software, including partnering with corporate sponsors to increase funding and expertise and involving end users in usability testing. ${ }^{2}$ 
Although few articles have presented usability tests of customizable library portals, numerous usability studies measuring the effectiveness of library Web sites provide templates that researchers can use as models in measuring the ease of use and functionality of library Web portals. Jeffry Rubin offered practical and comprehensive instructions for the usability testing process in the Handbook of Usability Testing: How to Plan, Design, and Conduct Effective Tests. ${ }^{3}$ Elaina Norlin and CM! Winters also offered a practical approach to usability testing in a library setting in Usability Testing for Library Web Sites: A Hands-on Guide. ${ }^{4}$ Susan Augustine and Courtney Greene supported the usability testing method as an effective means of gathering both quantitative and qualitative feedback about the design of a library Web site. ${ }^{5}$ Augustine and Greene measured the amount of time and number of clicks required to perform a given task against a benchmark "expert" value. ${ }^{6}$ In addition, they stressed the importance of recording the verbal feedback of users as they perform each task. ${ }^{7}$ Louise McGillis and Elaine G. Toms, Ruth Dickstein and Victoria A. Mills, Barbara J. Cockrell and Elaine Andreson Jayne, Brenda Battleson, Austin Booth, and Jane Weintrop, and Janet K. Chisman, Karen R. Diller and Sharon L. Walbridge all also offered practical models for assessing the usability of library Web sites and search tools..$^{8-12}$ These studies concur that usability testing of a group of no more than eight to ten subjects is an effective and cost-efficient means of gathering data pointing to problems in Web site functionality, design, and terminology.

In 2000, Todd Zazelenchuk and James Lane released the results of a usability study of the OneStart Portal, a prototype of a campuswide information portal for Indiana University. ${ }^{13}$ Although OneStart was not a library Web portal, the study measured user satisfaction with customization features unique to online portals, thus offering a practical model for the collection and compilation of usability study test data. In this study, usability test scores were divided into categories (e.g., overall flexibility, clarity of terms). ${ }^{14}$ As echoed in other Web site usability studies, "clarity of terms" proved to be an area in which users voiced greatest dissatisfaction with the portal. Most usability studies present participants with a series of explicit tasks. In a departure from this method, Zazelenchuk and Lane presented nine users with a printout of an already customized portal page and asked them to manipulate an uncustomized portal page until it matched the printout. ${ }^{15}$ This method is limited to usability tests of customizable applications. The authors claimed that this method eliminates the level of coaching implicit in usability tests that outline specific tasks in detail. ${ }^{16}$

In 2001, Justin Dopke and Gary Marchionini published the results of a usability test of the North Carolina State Library StartSquad Web Portal for Children. ${ }^{17}$ This test gathered and synthesized feedback of eight test subjects ranging from preschool to middle-school age. Usability study tasks were designed to measure suitability and recognizability of interface graphics, top-level navigation functions, information retrieval functions, and overall satisfaction with the interface. Due to the intended age of the audience, the study has somewhat limited applicability to the testing of a college-level tool such as the academic version of $\mathrm{My}$ Chicago Library. However, the authors' classification of task types can be easily applied to evaluative tests of academic library Web portals.

Since the team at North Carolina State University conceived of and released the MyLibrary software, numerous case studies and anecdotal articles have been published that recount the experiences of libraries implementing the software. These articles offer insight into issues ranging from the initial workload required for implementing MyLibrary to feedback from patrons about the usefulness of having a customizable library Web portal at their disposal. These articles are 
often brief and occasionally anecdotal in tone, but they help explain the need for customization in the evolving online environment. The December 2000 issue of Information Technology in Libraries compiles several case studies, including some about the implementation of MyLibrary at North Carolina State University, Virginia Commonwealth University, and Washington University. ${ }^{18}$ In this journal issue, Amos Lakos and Chris Gray argued that although portals will ultimately make libraries more customer centered and visible, librarians must realize the shift in work responsibilities and workload inherent in adopting and investing in a customizable library Web portal. ${ }^{19}$ In his 2003 article "Putting the 'My' in MyLibrary," Eric Lease Morgan contended that commercial sites such as Google.com or Amazon.com condition library users to expect automatic customization. ${ }^{20} \mathrm{He}$ argued that MyLibrary supplies library users with the convenience they have learned to expect from the commercial sector. $^{21}$

The Open University in the United Kingdom adapted the open-source MyLibrary software to create a customizable library Web portal for university students and faculty called MyOpenLibrary. ${ }^{22}$ Jane Lunsford published results of a study of MyOpenLibrary using a task-oriented usability test on eight subjects. She identified "a number of small problems with language and organization of the site." 23 Lunsford collected positive user feedback about the usefulness of the portal as a tool for organizing a "range of resources for a course." To date, her usability study of MyOpenLibrary is the only published research to evaluate the ease of use of the MyLibrary open-source software.

\section{Methodology}

A usability test consisting of a series of nineteen tasks was administered to eight prescreened participants recruited from the UIC community. The tasks were designed to test a range of portal functions with an emphasis on customization.
The time and actions taken to complete the tasks, as well as the participants' verbal comments, were recorded and analyzed.

At UIC, the Institutional Review Board (IRB) must approve studies involving human subjects. The investigators submitted a description of the study and all supporting documents such as questionnaires, advertisements, and usability tasks to the IRB and received exemption from federal regulations for the protection of human subjects. The research protocol ensured the confidentiality of all participants and that there was no potential to harm participants.

When IRB approval was obtained, the investigators began recruiting participants for the study. Flyers were created and posted in buildings on campus, and an announcement was posted on the campuswide electronic announcement board. To interest participants, the investigators offered an incentive in the form of a $\$ 15$ gift certificate redeemable at the campus bookstores, a provision of the original grant. Over the course of two weeks, the investigators received phone calls from respondents who were screened to determine their eligibility.

The investigators wanted to recruit participants with a range of computer skills and experience. To this end, a brief screening survey was designed and administered to each respondent over the telephone. The survey contained questions about experience using computers and familiarity with, and frequency of use of, library and Internet resources. (See appendix B.)

Approximately fifteen people responded to the recruiting advertisements and were given the screening survey. The investigators scheduled appointments with eleven respondents and conducted eight usability tests. The number of usability tests conducted was based on the literature. Jakob Neilsen posits in a column on his Web site, "Why You Only Need to Test with 5 Users" that the larger the test group, the more repetition will be 
revealed. ${ }^{25}$ According to the curve that illustrates this, 80 percent of the problems will be discovered with five users, eight users will uncover about 90 percent of the problems, and 100 percent of the problems will be revealed by fifteen users. In this vein, in their usability study of an Online Public Access Catalog (OPAC), Chisman, Diller, and Wallbridge claimed that "eight participants would identify $80 \%$ of the problems users might have with the system." 26

The usability tests were conducted over a two-week period. One-hour appointments were set with each user, and users were given a choice of a Windows ${ }^{\mathrm{TM}}$-based PC or Macintosh ${ }^{\mathrm{TM}}$ computer to use for their test. Individual tests took place in the investigators' offices with two investigators present. Participants were given a paper copy of the test to consult, and each task was read out loud by an investigator. Participants were encouraged to speak out loud while completing each task, giving explanations for their actions and commenting on their reactions to the content, appearance, and organization of the portal. One investigator recorded users' paths, noting each action a participant took to complete a task. A second investigator read the tasks aloud to the participant and recorded the amount of time spent on each task. It was unnecessary to take extensive notes detailing users' commentary at the time of the test because each session was audiotaped. However, the investigators recorded salient points and particularly strong participant reactions at the time of the testing so that it would be easier to isolate problematic areas when analyzing the data.

The investigators used the informal method of usability testing in which users were instructed to complete a set of tasks using the portal while "thinking out loud," voicing their thought process and comments, as suggested by Alison J. Head. ${ }^{27}$ Her recommendations of allowing users no more than four or five minutes to complete each task, for a total test time of no more than an hour, were followed as well. ${ }^{28}$

Before conducting the usability test on the participants, the investigators administered a pretest with three volunteers to make sure that the wording of the tasks was straightforward and to identify any errors, omissions, or problems with the tasks. This ensured that a user's performance would be based on the level of difficulty of a given task, not the complexity of the wording. It also ensured that any problematic tasks could be corrected prior to actual testing. Two versions of the test were written, with the nineteen tasks arranged in different orders, so that if user performance improved throughout the course of the test, it could not be attributed to the order of the tasks. Appendix A represents the tasks in the order they were performed by one group.

The tasks for the usability test were designed to test a wide range of portal functions. Though tasks varied, they fell into three categories the investigators named and defined: Administrative Functions, Category Recognition, and Content Manipulation. Administrative Functions are tasks related to a user's personal account or profile or the layout of the portal page, such as creating a new account, changing one's discipline, or altering the colors of the page. Tasks that required the user to find a resource based on its category name fall under Category Recognition. These tasks were designed to determine the usefulness of the terms used to name each section of the portal, such as "E-Journals," "Finding Articles," "Other Resources," and "Extras." Asking a user to link to the UIC History Department is an example of this type of task. Content Manipulation describes tasks in which the user is asked to alter the content of the portal, such as adding an electronic journal from the film discipline or creating a link to the New York Times in the MyLinks section. Some of the Content Manipulation tasks inherently involve Category Recognition as well because users must determine which section is to be customized. These task categories 
provided a framework for analyzing the qualitative and quantitative data according to the four goals of the study.

In addition to creating task categories, the investigators established benchmark paths and times for each task based on the amount of time and the number of actions it took the investigators to complete each task. These "expert paths" were the most direct route for completing a task. It was important to the validity of the test to determine beforehand what constituted an action. The investigators defined an action as any manipulation that changes the appearance of the portal page, such as pressing the "submit" button, resulting in a resource being added or removed, or clicking on a link that takes a user to a different page. Field entry, meaning marking an item in a list or entering text in a text field of a Web form, was counted as one action. Navigation within the portal page, such as clicking on an HTML anchor or scrolling up and down, was not counted as an action. A time limit of three minutes was set for each of the nineteen tasks, which kept the test to just under an hour. (The list of tasks is shown in appendix A.)

\section{The My Chicago Library Portal}

My Chicago Library is arranged into six customizable resource categories, one current awareness category, and a sidebar that lists library catalogs, Chicago community information, ready reference resources, and contact information. (See figure 1.) Unlike the resource categories, the sidebar cannot be altered by the user. In addition, a logo in the top left corner links to the library homepage, which serves as a brand for the My Chicago Library home institution. The top of the page displays the My Chicago Library banner, a stylized silhouette of the Chicago skyline. Beneath that is a navigation bar linking the user to all the administrative functions for managing a user account, customizing the color and layout of a page, and selecting a discipline. The discipline, which is intended to correspond to the UIC user's major and is chosen by the user, determines the resources that are delivered to the user's page. Directly beneath the navigation bar is a customizable title banner displaying the name of the portal, which can be personalized by the user. A navigation bar of HTML anchors linking to resource sections lies beneath the title, and, finally, the user's name and the date are displayed.

The content sections, labeled Services, Quick Searches, Finding Articles, Electronic Journals, Other Resources, My links, and Extras, can be edited to include

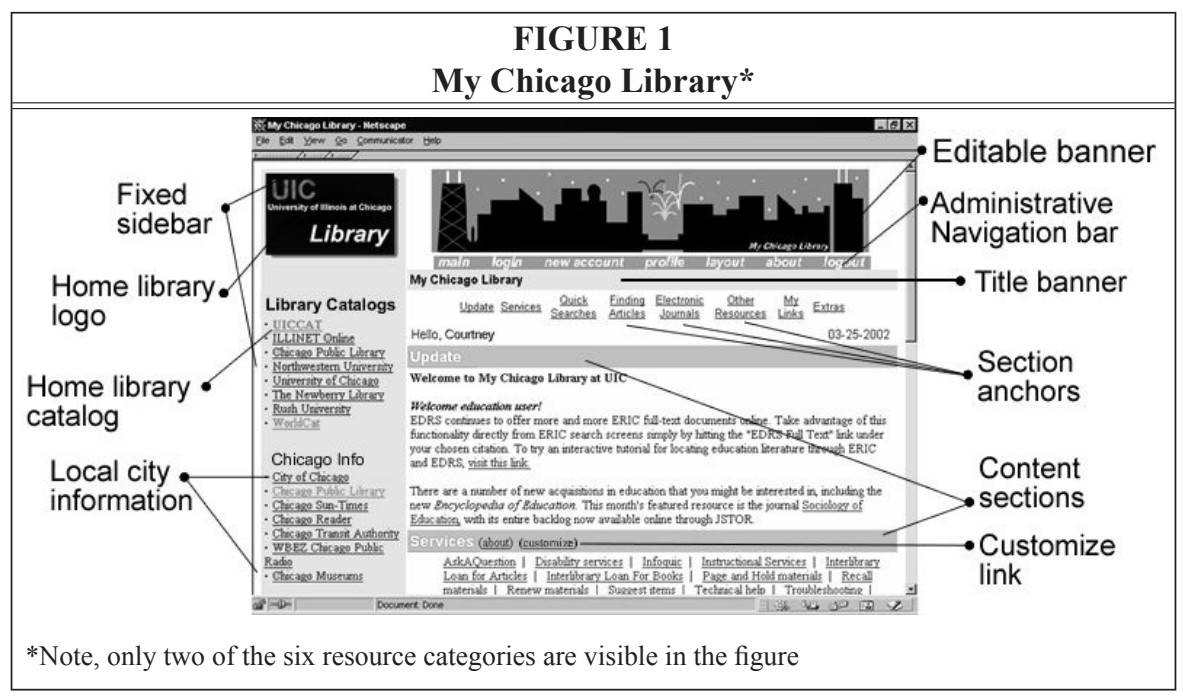


as much or as little content as the individual prefers. An exception is Updates, which is reserved for current awareness information delivered by the librarian who manages the user's discipline. The Services section links to interlibrary loan pages, circulation services, troubleshooting, and other library services. Quick Searches is a shortcut to search engines, thesauri, and dictionaries. Finding Articles displays discipline-specific article indexes and full-text content aggregators, and Electronic Journals lists high-impact journals available electronically. Other Resources is a catchall term to organize selected links to nonsubscription Web sites and discipline-specific Web resources that do not fit the other categories. MyLinks and Extras are additional sections that display personal bookmarks, news, and games.

\section{Results of Task Category Analysis}

Each task category defined in the methodology-Administrative Functions, Category Recognition and Content Manipulation-provided quantitative and qualitative data for accomplishing the first three goals of the study: to determine the clarity of the customization features and ease of navigation, to gather qualitative feedback on the layout and content of the portal, and to identify areas for improvement. The fourth goal, to measure participants' perceptions of the portal as a tool for research, was accomplished through analysis of qualitative data from user feedback.

\section{Administrative Functions Tasks}

Administrative Functions tasks had the greatest impact on evaluating the ease of customizing the portal. These tasks changed the background color, banner and text colors, and the layout of the portal. If Administrative Functions tasks were completed, the design of the customization features and navigation was considered to be effective.

Screening survey data revealed that the participants were familiar and com- fortable with Internet applications. (See appendix B.) The majority of participants rated themselves at the highest level (5 on a scale from 1 to 5 ) in terms of their comfort and skill with computers and the Internet. All eight test participants recorded at least three years of computer use, five participants had used computers for five to seven years, and two had at least ten years of experience. All the participants reported that they used the Internet every day. Although the participants self- reported a high level of comfort with computers and the Internet (daily Internet use might indicate competency), these are by no means standardized measures and are not intended to prove the participants' skill levels, but only to indicate their own perceptions of their computer skills.

Of the Administrative Functions tasks, all the participants completed tasks 1, 2, and 3. (See table 1 for a complete list of tasks and scores grouped by category.) Task 4 was completed by five participants, and task 5 was completed by four participants. That 83 percent of Administrative Functions tasks were completed suggests that the customization features of $\mathrm{My}$ Chicago Library were conceptually clear and visually apparent.

For this study, all participants were instructed to select history as their discipline so that all resources would be identical for every test. Examination of the average time required for the Administrative Functions tasks shows that tasks 1, 4, and 5 required two or three times as long as the expert's benchmark time. Of the Administrative Functions tasks, 4 and 5 were also the tasks that participants were most often unable to complete. The 50 percent completion rate for task 5, "change your discipline," may have occurred because the participants were instructed to select history as their discipline. Because this requirement of the study prevented them from selecting their own discipline, they may not have been as aware of the importance of making a personalized selection. If a given participant was a history major, he or she 


\begin{tabular}{|c|c|c|c|c|c|c|c|c|c|}
\hline & & $\begin{array}{r}\text { TA } \\
\text { sks A }\end{array}$ & $\begin{array}{l}\mathrm{LE} \\
\mathrm{d} \mathbf{S}\end{array}$ & ores & & & & & \\
\hline & Tasks Grouped by Category & 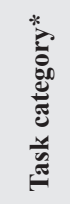 & 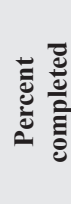 & 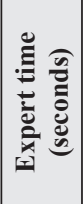 & 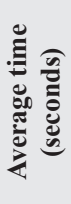 & 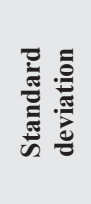 & 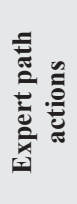 & 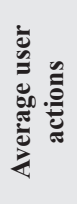 & 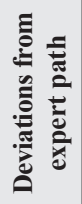 \\
\hline 1 & Create a new account & $\mathrm{AF}$ & 100 & 50 & 105 & 32.08 & 4 & 4.6 & 2 \\
\hline 2 & $\begin{array}{l}\text { Change the background } \\
\text { color }\end{array}$ & $\mathrm{AF}$ & 100 & 14 & 23 & 15.90 & 3 & 3 & 0 \\
\hline 3 & $\begin{array}{l}\text { Log out of My Chicago } \\
\text { Library. Then log in again }\end{array}$ & $\mathrm{AF}$ & 100 & 22 & 30 & 14.15 & 5 & 5 & 0 \\
\hline 4 & $\begin{array}{l}\text { Change the title to "My } \\
\text { Strawberry" }\end{array}$ & $\mathrm{AF}$ & 62.5 & 26 & 70 & 50.67 & 4 & 5.8 & 11 \\
\hline 5 & $\begin{array}{l}\text { Change your discipline to } \\
\text { "psychology" }\end{array}$ & $\mathrm{AF}$ & 50 & 16 & 59 & 33.37 & 3 & 4.5 & 11 \\
\hline 6 & $\begin{array}{l}\text { Link to the UIC History } \\
\text { Department }\end{array}$ & $\mathrm{CR}$ & 100 & 9 & 70 & 58.36 & 2 & 4.9 & 13 \\
\hline $7 * *$ & $\begin{array}{l}\text { Find the definition of the } \\
\text { word neologism }\end{array}$ & $\mathrm{CR}$ & 100 & 17 & 21 & 8.41 & 3 & 2.5 & 2 \\
\hline 8 & $\begin{array}{l}\text { Link to the library catalog } \\
\text { you would use to get the call } \\
\text { number for this book }\end{array}$ & $\mathrm{CR}$ & 87.5 & 8 & 42 & 58.24 & 1 & 1.9 & 3 \\
\hline 9 & $\begin{array}{l}\text { Use the portal to recall a } \\
\text { book }\end{array}$ & $\mathrm{CR}$ & 100 & 3 & 28 & 23.28 & 1 & 2.6 & 7 \\
\hline 10 & $\begin{array}{l}\text { Find today's Chicago Sun- } \\
\text { Times headline }\end{array}$ & $\mathrm{CR}$ & 50 & 10 & 14 & 10.84 & 2 & 2 & 0 \\
\hline $11 * *$ & $\begin{array}{l}\text { Remove the link to } \\
\text { "Archives USA" }\end{array}$ & $\begin{array}{l}\mathrm{CR} / \\
\mathrm{CM}\end{array}$ & 100 & 20 & 35 & 31.30 & 4 & 4.4 & 2 \\
\hline 12 & $\begin{array}{l}\text { Remove the link to "Sports } \\
\text { Scores" }\end{array}$ & $\begin{array}{l}\mathrm{CR} / \\
\mathrm{CM} \\
\end{array}$ & 100 & 11 & 24 & 15.26 & 3 & 4.2 & 5 \\
\hline 13 & $\begin{array}{l}\text { Create a link to the New } \\
\text { York Times Web site }\end{array}$ & $\mathrm{CM}$ & 100 & 30 & 45 & 21.75 & 4 & 4.9 & 1 \\
\hline 14 & $\begin{array}{l}\text { Remove the link to the elec- } \\
\text { tronic journal International } \\
\text { Review of Social History }\end{array}$ & $\mathrm{CM}$ & 100 & 17 & 50 & 33.70 & 4 & 4.5 & 3 \\
\hline 15 & $\begin{array}{l}\text { Add a resource to the "Other } \\
\text { Resources" section from the } \\
\text { film discipline }\end{array}$ & $\mathrm{CM}$ & 50 & 25 & 90 & 57.38 & 5 & 5 & 5 \\
\hline 16 & $\begin{array}{l}\text { Add an electronic journal } \\
\text { to the "Electronic Journals" } \\
\text { section from the alphabeti- } \\
\text { cal list }\end{array}$ & $\mathrm{CM}$ & 87.5 & 29 & 58 & 18.88 & 5 & 6 & 5 \\
\hline $17 * *$ & $\begin{array}{l}\text { Add a link to the electronic } \\
\text { journal Asian Art }\end{array}$ & $\mathrm{CM}$ & 62.5 & 31 & 96 & 64.52 & 5 & 5.4 & 7 \\
\hline
\end{tabular}




\begin{tabular}{|l|l|l|l|l|l|l|l|l|l|}
\hline \multicolumn{10}{|c|}{ TABLE 1 } \\
\hline \hline
\end{tabular}

might recognize the resources delivered to his or her page as relevant to history. Participants majoring in chemistry, for example, would be unlikely to recognize the resources delivered to their page and therefore might not make the connection between selecting a discipline in My Chicago Library and seeing the relevant resources on their page. Thus, being asked to change one's discipline might not have the implicit importance that it would have had, had they first chosen a familiar area of study.

Tasks 4 and 5 asked the users to make changes to the portal's appearance and to their academic discipline or, as labeled in the portal, their profile. To make these changes, users must navigate to an administrative editing page and make selections from a list of options. My Chicago Library displays two navigation bars along the top of the screen. (See figure 1.) The uppermost navigation, with links to "new account," "layout," "profile," and "login" take the user out of the portal to the aforementioned administration page. The other navigation bar is a horizontal list of HTML anchors that are internal links to the resource sections further down the page. Because participants must use the upper navigation bar to complete Administrative Functions tasks, low completion rates indicate that they either could not find or did not understand the labels on the navigation bar.

\section{Category Recognition Tasks}

Completion of the second task type, Category Recognition, required participants to understand the type of electronic resource they were adding, removing, or linking to and the label of the section into which that resource was grouped. These tasks aided in the analysis of the portal's ease of navigation.

The results of Category Recognition tasks 6 and 8, "Link to the UIC History Department" and "link to the library catalog you would use" illustrate important navigational issues. All the participants completed task 6, and only one participant did not complete task 8. Despite this high completion rate, on average, the tasks required a great deal of time to finish. Participants spent a lot of time reviewing the portal page for the correct choice or following incorrect links.

The link to the UIC History Department is listed in the "Other Resources" section, and the library catalog is listed 
in the sidebar. "Other Resources" is a catchall category for resources such as academic departments or Web sites that do not fit into the categories of electronic journals, article databases, or library services. The participants recognized that the UIC History Department was not an article database or electronic journal and therefore was not listed in those sections, but they found the label "Other Resources" to be too vague. This may indicate that the users tried to find explicit, meaningful categories for the answers rather than catchall categories such as "other."

The UIC library catalog is within a section of the sidebar labeled "Library Catalogs" and is, in fact, the top choice in that list, a parameter controllable by the librarian administrator of My Chicago Library. It is possible that participants overlooked the sidebar because it cannot be customized and is not part of the central content of the portal page. For this reason, they might have spent the majority of the allotted time scanning the portal page before finding the catalog link.

There was a high number (13) of navigational deviations from the expert path for task 6. By examining the navigational deviations made in this task and in other tasks, salient examples were discovered pertaining to the problems encountered with Category Recognition tasks. Five participants made thirteen navigation actions more than were necessary before completing the task. Participants did not understand that the UIC History Department link would be included in their customized portal even after they had been instructed to create a profile as a history major. One participant put it succinctly, saying, "I didn't realize it was customized to someone in history. Like, if it was [customized] in biology, the UIC biology department would be there." Before this task, some of the participants had not ascertained that by creating a profile in the portal, they were selecting discipline-specific resources.
Fifty percent of the participants did not complete Category Recognition task 10, "Find today's Chicago Sun-Times headline." Like the UIC catalog, the link to the newspaper is located in the sidebar, in an area populated with Chicago community information and ready reference sources. Completion of this task may indicate that users understood why the Chicagooriented content was included and why it was located in the sidebar. Participants who did not complete the task overlooked the sidebar and spent time trying to find the newspaper in one of the library resource categories.

In the analysis of Category Recognition tasks, investigators recorded a total of 32 additional (and superfluous) actions made by the participants. These navigational actions, which deviate from the expert path, raised the average actions per task and suggest that the participants used trial and error rather than an understanding of the portal organization. The screening survey reveals that the majority of participants had never received any library instruction. (See appendix B.) This may explain some of the participants' navigational deviations because sections are labeled with library-specific terms that students might only be familiar with through library instruction. Augustine and Greene noted in their library Web site usability study that "especially noteworthy were the participants' difficulty with library terminology and their lack of knowledge of library resources." ${ }^{29}$ Even a Web research tool with a high level of visual and navigational clarity will be confusing if the end users do not understand the descriptive language used to identify categories of information.

\section{Content Manipulation Tasks}

The third task category, Content Manipulation, requires users to add or remove portal content and combines actions required by Category Recognition tasks and Administrative Functions tasks. Thus, Content Manipulation tasks were used to evaluate two of the primary 
goals of the study: determine the clarity of the customization features and ease of navigation. Of the three task categories, Content Manipulation tasks had the lowest completion rate.

Content Manipulation tasks also had the highest average number of deviations from the expert path. When performing Content Manipulation tasks, users navigated to a customization page where content choices were listed in three groups. First, current or default selections were listed next to check boxes. By adding or removing check marks, users can add or remove resources. Second, users can view an alphabetical list of all the resources in that section. Third, they can view a list of all resources designated for that discipline. The high incidence of deviations from the expert path indicated that participants were scanning the edit page without easily recognizing which type of listing to review. For example, one participant sought an answer by viewing resources listed by discipline, when searching for the resource from the alphabetical list would have been a more efficient choice.

In addition to the deviations from the expert path, the time spent completing Content Manipulation tasks suggested difficulty in understanding the way the resources were organized in the portal. The average times recorded for tasks 15 and 17 ("Add a resource to the 'Other Resources' section" and "Add a link in the Electronic Journals section to the electronic journal Asian Art") were three times those of the expert's time. In task 15, participants may not have recognized that two actions were necessary to view the list of resources. In addition to selecting "customize" from the "Other Resources" title bar, they must select to view the resources either alphabetically or by discipline.

The Content Manipulation task category is arguably the most difficult to perform because it requires an understanding of the Administrative Functions and Category Recognition tasks, in addition to requiring the greatest number of actions to complete. After making one or more changes to a section, users have to click on a "submit" button to complete the change. The changes are then displayed within the list of current resources. At this point, users can continue to customize or, if satisfied with the changes, can navigate back to their portal page through a "Return to MyLibrary" link. Participants said that this sequence was confusing. They were unsure that their edits had been successful and they wanted clearer confirmation of this. Some participants suggested that a pop-up dialog box stating the changes would be helpful. This desire for confirmation stands in contrast to users' comments about the account creation page. Those comments suggested that the portal provided too much explanation.

\section{Qualitative Feedback}

Participant commentary provided the investigators with much useful information about navigation, layout, usability, and user comprehension of the design intent of the portal. Navigation problems were identified when participants commented that many pages were too long and required too much scrolling. Participants made these comments when they were adding or removing resources from the customization page. Lists of resources are generated by the MyLibrary portal and can be very long depending on the number of resources in the database. My Chicago Library did not contain any navigational management tools for these lists. Participants suggested that the lists contain "back-to-top" links and HTML anchors linking to sections within the lists.

Participants' responses to the activities required for account creation revealed many usability issues. These comments were particularly important because they correlate with the first encounter a new user has with My Chicago Library. The form for creating a new account contains several text boxes and radio buttons, all of which require some action or text entry from the user. Next to each text 
entry field is a text-based help link, which provides an explanation of the information users need to enter. While creating a new account, one participant noted: "I don't think the tab button is working. It is frustrating. I want to move from text box to text box and the tab button won't automatically go there." The user became frustrated when attempting to use the tab key instead of the mouse to place the cursor in the next field because the cursor advanced to the help link associated with that field before moving on to the next field.

Participants also were critical of the login process. Following the login, but before a user is directed to their portal page, an intermediate page asks them if they want to place a cookie in the browser cache that would retain their login information. The rationale for incorporating this intermediate page arose from a concern that many users would be accessing My Chicago Library from public workstations and that automatically saving the user's login information risked user privacy. Participants commented that this page was unnecessary and held too much explanatory information. Web design convention handles this issue by placing a small checkbox next to the login fields labeled "remember my user name" or "remember me on this computer."

Some participants complained that they did not automatically return to their portal page after submitting a change from the customization page. After the "submit" button is clicked, the portal updates the customization page to include the most recent changes. Only when users click on the "Return to My Chicago Library" link are they redirected to their portal page.

Other critical comments related to the "Quick Search" function. The "Quick Search" section, located below the library services section, presents the user with a text entry field and a choice of Internet search resources such as Google.com ${ }^{\mathrm{TM}}$, Dictionary.com ${ }^{\mathrm{TM}}$, or Bartleby.com ${ }^{\mathrm{TM}}$. The "Quick Search" is a shortcut to content.
Contrary to the designer's expectations, the participants expected the "Quick Search" to perform an internal search of the portal, not a search of the World Wide Web. They expressed surprise that the search box was positioned in a content section and said that a site search function should be located in a corner of the page. My Chicago Library does not provide a site search function in the way that users desired, in part because it is not composed of static HTML files containing textual content that can be searched. Unlike a static Web site, My Chicago Library generates each user's portal page from content in a relational database. The users' assumption that the "Quick Search" provided a site search and was therefore a navigational tool indicates their misunderstanding of the portal as a content tool.

Participants commented that the sidebar was too cluttered, too lengthy, and a poor use of window space. Some told the investigators that they did not need the Chicago community information and would not use it, which indicated that the participants were not interested in the portal as a Chicago community-centered resource and suggests the importance of the participants' orientation as UIC students above their orientation as citizens of Chicago. They also stated that menus presented as lists in the sidebar wasted page space. They suggested using pulldown menus instead.

My Chicago Library for UIC was designed to complement the library's Web site. The portal did not include a link to the University Web site in its tested incarnation. The UIC icon branding the portal went to the UIC library. To the surprise of the investigators, the participants suggested that a home button be included that would return them to the university homepage. They expected links to university services and student services. The designers and investigators possessed an orientation to the library whereas the test participants appeared to have a broader viewpoint. Comments such as "I would like to see headlines or 
UIC news" indicate that they did not differentiate between the university's Web presence and the library's Web presence in the same way that the portal designers and the investigators did. Participants misapprehended the scope of the portal because they expected a university-wide orientation and not a portal limited to library resources.

The investigators received several positive comments and a great deal of constructive criticism from the participants about the proposed implementation of the portal. Participants responded enthusiastically to the portal, despite their lack of a full understanding of its intended purpose. Comments about the service, such as "I would definitely use it if the library offered it," "it is very intuitive," and "it is very user-friendly," suggested the participants' estimation of the portal as a useful research tool. Participants stated that they would require some time to "play" with the portal, familiarizing themselves with its content and functions, but that they would return to it when they had customized it. Although these comments indicate that the portal requires a time investment to customize, other qualitative feedback suggests that the portal would be a useful library service.

\section{Redesign Suggestions}

This study confirmed the need for succinct instructions. Participants indicated a preference for visual cues such as buttons or icons rather than textual explanations. The text-based help links on the "account creation" page were an impediment to some users. Participants also commented on the lengthiness of instructions on the account creation page, the login page, and the editing pages. The majority of study participants reported a high level of computer skill; therefore, the help texts associated with making selections from lists or common Web activities such as completing and submitting Web forms may be unnecessary.

It is possible that this sample of highly skilled users may have suggested design changes that less experienced users would find difficult to navigate. However, it should be noted that the participants' levels of computer skills were self-reported. The investigators did not perform any objective evaluation of skills as those skills might be defined by a standard measure. Without a standard by which to evaluate the participants, the self reported skill levels must be viewed as levels of confidence and comfort with computers and the Internet rather than objectively evaluated abilities. The participants' scores in the study, whether they were close to the expert scores or not, do not in and of themselves support the participants' claims of expertise. Given this, design suggestions resulting from the study and from participant suggestions do not necessarily indicate that less experienced - or rather less comfortable- users would have greater difficulty with the changes.

Despite the ease with which the customizations were made, the participants wanted explicit confirmation that Content Manipulation changes had actually gone through. A small icon or textual explanation that appears whenever a form is submitted could solve this issue.

The difficulty that participants had with Category Recognition tasks indicates that the section labels need to be easier to understand. Given the wellestablished problems users have with library terminology, one possible remedy to this issue would be to use labels that identify the type of content listed rather than the type of resource listed. For example, rather than the label "Finding Articles," which stresses the process of the search rather than the desired product, the section could be labeled "Journal Articles." In addition, the label "Electronic Journals" could be changed to "History Journals" or "Film Journals," depending on the user's discipline. Because so much periodical literature is available in full-text, the distinction that librarians draw between electronic journals and paper journals may no longer be as 
relevant as a few years ago when e-journals were new and had limited content. The label "Magazines and Journals," as general as that may sound to a librarian, might be a better choice than "Electronic Journals."

The study identified many areas for improvement in the use of page space. Participants repeatedly suggested spacesaving techniques and improvements to the layout of the sidebar, the services options, and to the list of resource options on the customization pages. Participants suggested compact lists and menus, such as drop-down menus, or mouse-over menus to avoid long scrolling pages.

Finally, participants wanted a bright and colorful portal. They approved of the Chicago skyline banner but felt that the default gray for the section labels was drab and uninviting. Even though the styles and colors were customizable by the user, the test group suggested that the default page of My Chicago Library needed a more professionally designed look.

\section{Conclusions}

The users in this study appeared to have difficulty understanding the disciplinespecific nature of the My Chicago Library portal. Following instructions to create a history account rather than making personal selections may have hindered users from understanding the level of control they had over the portal content. In designing a study in which all users performed the same tasks with the same content, the investigators may have inadvertently prevented participants from learning and understanding the intended purpose of the portal. Moreover, the participants suggested that the portal include university services and university headlines. This request and their presumption that the UIC logo be linked to the university homepage rather than to the library indicate a different orientation to the library than the designers expected. The participants considered the university to be the next logical par- ent site as opposed to the library's main homepage.

Study results indicate that even experienced computer users struggle with customizing My Chicago Library. However, results also suggest that when users overcome this learning curve, they appreciate the shortcuts offered by the portal. The individualized pages direct users to crucial resources and provide shortcuts through the universe of information available from the library. My Chicago Library can be a useful alternative to traditional library Web sites in which users must navigate through many layers of pages to reach the resources they seek.

Although appreciative of the streamlined access the portal provides, some participants stated that they would use the "customize" tool to include all the resources from their discipline to ensure a comprehensive list of relevant resources. This comment and others suggested to the investigators that users want to select high-quality resources in their discipline, but they resist any other limitations on their options.

Objections to the lengthy explanations, overly long lists, and ubiquitous help links showed the investigators that My Chicago Library navigation needs to conform to common Web features by including shorter pages or making page sections easily accessible through the use of anchors. This is especially important when managing potentially long lists. Designers should value clarity of visual layout and minimize textual explanations in future iterations of the portal.

This study bolsters Augustine and Greene's assertions that user misunderstanding of librarian-defined resource categories remains a serious stumbling block to library Web site usability. ${ }^{30} \mathrm{Li}$ brarians must label resources using common language, even at the risk of incomplete or slightly inaccurate descriptions. As demonstrated by participants in this study, users frequently misunderstand how libraries organize information if they have not had library instruction. 


\section{Implications and Suggested Research}

Since this study was performed, the UIC library has implemented MyLibrary version 2.63, dubbing it MyLibrary@UIC. The portal now more closely resembles the UIC library Web site and incorporates the colors and the finished quality that test participants requested. Also, the list of disciplines has been expanded to include all courses of study at UIC. An FAQ page explaining the portal's purpose and functionality has been added. Currently, the library is investigating ways to incorporate automated methods of uploading electronic resources into the MyLibrary database.

In future studies, a screening survey revealing the participants' experience with customizable Web products might be helpful. An exit survey designed to collect detailed perceptions of the portal also could provide valuable data, as would a standard measure of computer skills. The investigators anticipate conducting another usability study following the changes made to the My Chicago Library portal based on study findings and after implementing new versions of the MyLibrary software.
By designing the study to measure the completion of specific tasks in My Chicago Library, the investigators were able to identify both problems and good design elements of MyLibrary as modified for Chicago-area UIC students and faculty. By creating tasks that fall into three categories of use-Administrative Functions, Category Recognition, and Content Manipulation, the study helps the investigators understand the participants' behavior in a conceptual framework. Results viewed in this framework allow librarians to apply data or lessons learned to other Web-based interactive research tools. As Web functionality expands and becomes more complex, interactions with Web-based research tools can be improved by usability testing that incorporates functional categories to the test design. This study and others like it may help libraries determine how to incorporate a portal into their electronic services or how to create a portal that meets the research needs of their user population. The investigators hope that this study will assist librarians in creating intuitive and user-friendly research tools, and provide a template for librarians conducting usability testing on library research tools.

\section{APPENDIX A List of Tasks in the Order in Which They Were Performed}

1. Create a new account. Use "buttercup" as your user name and "Illinois" as your password. Select "history" as your discipline. When you are logged in, select "Just show me my page."

2. Create a link to the New York Times Web site (http://www.nytimes.com/) in your "My Links" section. Then return to My Chicago Library.

3. Link to the UIC History Department. Then click the browser's "Back" button to return to My Chicago Library.

4. Remove the link from the "Electronic Journals" to the electronic journal International Review of Social History. Then return to My Chicago Library.

5. Change the background color of My Chicago Library to yellow.

6. Log out of My Chicago Library. Then log in again. When you are logged in, select "Just show me my page." 
7. Add a resource to the "Other Resources" section from the film discipline. Then return to My Chicago Library.

8. Add an electronic journal to the "Electronic Journals" section from the alphabetical list of electronic journals. Then return to My Chicago Library.

9. Use the portal to find the definition of the word neologism.

10. Remove the link to "Archives USA." Then return to My Chicago Library.

11. Add a link in the "Electronic Journals" section to the electronic journal Asian Art. Then return to My Chicago Library.

12. The UIC library owns the novel A Day Late and a Dollar Short. Link to the library catalog you would use to get the call number for this book. Then click the browser's "Back" button to return to My Chicago Library.

13. Remove the link to "Sports Scores."

14. The novel A Day Late and a Dollar Short is checked out. Use the portal to recall it.

15. Change your discipline to "psychology." Merge your presently customized selections with the suggested selections of the new discipline.

16. Remove "Sage Family Studies Abstracts" from the "Finding Articles" section. Then return to My Chicago Library.

17. Change the title of "My Chicago Library" to "My Strawberry."

18. Add two databases to the "Finding Articles" section from the sociology discipline. Then return to My Chicago Library.

19. Find today's Chicago Sun-Times headline. Then click the browser's "Back" button to return to My Chicago Library.

\section{APPENDIX B \\ The Participant Screening Survey}

How long have you been using a computer?

\begin{tabular}{|c|c|c|c|c|}
\hline $0-1$ years & $1-3$ years & $3-5$ years & $5-7$ years & More than 10 years \\
\hline 0 & 0 & 1 & 5 & 2 \\
\hline
\end{tabular}

What kinds of things do you use the computer to do?

\begin{tabular}{|c|c|c|c|c|}
\hline Word processing & Internet searching & Online chat & E-mail & other \\
\hline 8 & 8 & 7 & 8 & 8 \\
\hline
\end{tabular}

What is your status at the University of Illinois at Chicago?

\begin{tabular}{|c|c|c|c|}
\hline undergraduate & graduate & faculty & staff \\
\hline 0 & 7 & 0 & 1 \\
\hline
\end{tabular}


How much experience do you have using the UIC library?

\begin{tabular}{|c|c|c|}
\hline Never used & Occasional use (once a month) & Frequent use (once a week) \\
\hline 0 & 3 & 5 \\
\hline
\end{tabular}

Have you had a library instruction session?

\begin{tabular}{|c|c|}
\hline yes & no \\
\hline 2 & 6 \\
\hline
\end{tabular}

Which of the following UIC library resources have you used on the World Wide Web?

\begin{tabular}{|c|c|c|c|}
\hline UICCAT & Article databases & Electronic journals & Electronic reference materials \\
\hline 8 & 3 & 5 & 4 \\
\hline
\end{tabular}

How often do you use the Internet?

\begin{tabular}{|c|c|c|c|}
\hline Never & Rarely (once a month) & Occasionally (once a week) & Frequently (once a day) \\
\hline 0 & 0 & 0 & 8 \\
\hline
\end{tabular}

On a scale from 1 to 5 with 1 being low and 5 being high, how would you rate your comfort with using computers in general?

\begin{tabular}{|l|l|l|l|l|}
\hline 1 & 2 & 3 & 4 & 5 \\
\hline 0 & 0 & 1 & 1 & 6 \\
\hline
\end{tabular}

On a scale from 1 to 5 with 1 being low and 5 being high, how would you rate your comfort with using Internet resources?

\begin{tabular}{|l|l|l|l|l|}
\hline 1 & 2 & 3 & 4 & 5 \\
\hline 0 & 0 & 2 & 1 & 5 \\
\hline
\end{tabular}

On a scale from 1 to 5 with 1 being low and 5 being high, how would you rate your skill at using computers in general?

\begin{tabular}{|l|l|l|l|l|}
\hline 1 & 2 & 3 & 4 & 5 \\
\hline 0 & 1 & 0 & 3 & 4 \\
\hline
\end{tabular}

On a scale from 1 to 5 with 1 being low and 5 being high, how would you rate your skill at using Internet resources?

\begin{tabular}{|l|l|l|l|l|}
\hline 1 & 2 & 3 & 4 & 5 \\
\hline 0 & 11 & 1 & 2 & 4 \\
\hline
\end{tabular}

Are you more comfortable using a PC or a Mac?

\begin{tabular}{|c|c|}
\hline PC & Mac \\
\hline 8 & 0 \\
\hline
\end{tabular}




\section{Notes}

1. David M. Nichols and Michael B. Twidale, "The Usability of Open Source Software,"

First Monday 8, no. 1 (Jan. 2003). Available online at http://firstmonday.org/issues/issue8_1/ nichols/index.html. [Accessed 14 February 2005].

2. Ibid.

3. Jeffrey Rubin, Handbook of Usability Testing: How to Plan, Design, and Conduct Effective Tests (New York City: Wiley, 2002).

4. Elaina Norlin and CM! Winters, Usability Testing for Library Websites: A Hands-on Guide (Chicago: ALA, 2002).

5. Susan Augustine and Courtney Greene, “Discovering How Students Search a Library Web Site: A Usability Case Study," College \& Research Libraries 63, no. 4 (July 2002): 354-65.

6. Ibid., 357.

7. Ibid., 358 .

8. Louise McGillis and Elaine G. Toms, "Usability of the Academic Library Web Site: Implications for Design. Study at the Memorial University of Newfoundland," College \& Research Libraries 62, no. 4 (July 2001): 355-67.

9. Ruth Dickstein and Victoria A. Mills, "Usability Testing at the University of Arizona Library: How to Let the Users in on the Design," Information Technology and Libraries 19, no. 3 (Sept. 2000): $144-51$.

10. Barbara J. Cockrell and Elaine Anderson Jayne, "How Do I Find an Article? Insights from a Web Usability Study at Western Michigan University," Journal of Academic Librarianship 28, no. 3 (May 2002): 122-32.

11. Brenda Battleson, Austin Booth, and Jane Weintrop, "Usability Testing of an Academic Library Web Site: A Case Study at SUNY Buffalo," Journal of Academic Librarianship 27, no. 3 (May 2001): 188-98.

12. Janet K. Chisman, Karen R. Diller, and Sharon L. Walbridge, "Usability Testing: A Case Study at Washington State University," College \& Research Libraries 60, no. 6 (Nov. 1999): 552-69.

13. Todd Zazelenchuk and James Lane, "OneStart Portal Usability Report: Electronic Prototype Test Results and Recommendations, Tested November 2000." Available online at http://www. indiana.edu/ usable/reports/test2_report.pdf. [Accessed 18 February 2005].

14. Ibid., 7.

15. Ibid., 5 .

16. Ibid.

17. Justin Dopke and Gary Marchionini, "Report of the Results of a Usability Test of the North Carolina State Library StartSquad Web Portal for Children, University of North Carolina- Chapel Hill, 2001." Available online at http://ils.unc.edu/idl/Kids_portal_final_report.pdf. [Accessed 14 February 2005].

18. Amos Lakos and Chris Gray, "Personalized Library Portals as an Organizational Culture Change Agent," Information Technology and Libraries 19, no.4 (Dec. 2000): 169-74.

19. Ibid., 172. $24-27$.

20. Eric Lease Morgan, "Putting the 'My' in MyLibrary," Library Journal 128, no. 17 (fall 2003):

21. Ibid., 26.

22. Jane Lunsford, "MyOpenLibrary: Personalized Library Resources. Report on a Usability Evaluation, May 12th, 13th, 14 ${ }^{\text {th }}$, 2003." Available online at http://library.open.ac.uk/aboutus/myolib/reports.htm. [Accessed 5 January 2004].

23. Ibid.

24. Ibid.

25. Jakob Nielsen, "Why You Only Need to Test with 5 Users: Jakob Nielsen's Alertbox." Available online at http://www.useit.com/alertbox/20000319.html. [Accessed 14 February 2005].

26. Chisman, Diller, and Walbridge, “Usability Testing," 553.

27. Alison J. Head, "Web Redemption and the Promise of Usability," Online 23, no. 6, (Nov./Dec. 1999): 20-28.

28. Ibid.

29. Augustine and Greene, "Discovering How Students Search a Library Web Site," 364.

30. Ibid., 358. 